\title{
Green Synthesis of Silver Nanoparticles Using Moringa Oleifera Leaf Extract, Tamarindus Indica Fruit Extract and Assessement of Antibacterial Activity Against Staphylococcus Aureus
}

\section{Shirisha A}

College of Veterinary Science Rajendranagar

ANUMOLU VIJAYA KUMAR ( $\sim$ vphanumolu@gmail.com )

College of Veterinary Science Rajendranagar https://orcid.org/0000-0002-7852-5929

Laxman Chatlod R

National Research Centre on Meat

Shashi Kumar M

College of Veterinary Science Rajendranagar

Krishnaiah $\mathbf{N}$

College of Veterinary Science Rajendranagar

Raghupathi Ch

College of Veterinary Science Rajendranagar

\section{Research Article}

Keywords: Silver nanoparticles, Moringa oleifera, Tamarindus indica, Characterization, Antibacterial activity

Posted Date: November 15th, 2021

DOI: https://doi.org/10.21203/rs.3.rs-1082171/v1

License: (c) (i) This work is licensed under a Creative Commons Attribution 4.0 International License. Read Full License 


\section{Abstract}

The present study mainly deals with the green synthesis, characterization and evaluation of antibacterial properties of silver nanoparticles (AgNPs) synthesized by using the leaf extract of Moringa oleifera and fruit extract of Tamarindus indica. In this study for synthesis of silver nanoparticles different ratios of $1 \mathrm{mM}$ silver nitrate and Moringa oleifera leaf extract i.e, 95:5, 90:10 and 85: 15 was taken in conical flask and kept for one $1 \mathrm{hr}$ at $250 \mathrm{c}$ on magnetic stirrer, out of which 90:10 ratio was selected for further study based on highest peak, good size and stability. Tamarindus indica fruit extract was added to silver nitrate solution till the colour of the solution changes from light brown to chocolate brownish colour. The synthesized silver nanoparticles were characterized by UV-Visible spectroscopy, Zeta potential, size distribution by intensity. The absorption spectrum of the silver nano solution prepared by using Moringa oleifera and Tamarindus indica fruit extract showed a surface plasmon absorption band with maximum of $420 \mathrm{~nm}$ and $430 \mathrm{~nm}$ respectively indicating the presence of silver nanoparticles. The zeta value of silver nanoparticles synthesized from Moringa oleifera and Tamarindus indica fruit extract was $-12.5 \mathrm{mV}$ and $-15.5 \mathrm{mV}$, size of $110.2 \mathrm{~nm}$ and $130.2 \mathrm{~nm}$ respectively. The antibacterial efficacy of nanosilver was checked by agar well diffusion method, and the silver nanoparticles showed effective antibacterial activity against Staphylococcus aureus.

\section{Introduction}

Nanotechnology is the ability to control and restructure the matter at the atomic and molecular levels in the range of approximately $1-100 \mathrm{~nm}$ and exploiting the distinct properties and phenomena at that scale as compared to those associated with single atoms or molecules or bulk behaviour (1). The most important and distinct property of nanoparticles is that they exhibit larger surface area to volume ratio (2). The noble metal nanoparticles exhibit new physicochemical properties which are not observed either in the individual molecules, or in the bulk metals (3). Control of size, composition, morphology, stability and environmental friendly synthesis are the features which are highly desirable. Noble metal nanoparticles, such as $\mathrm{Ag}, \mathrm{Au}, \mathrm{Pt}$, and $\mathrm{Pd}$ nanoparticles are used in physical, chemical and biological applications (4).

Silver nanoparticles represents a good candidate to carry out the nanostructured part of antibacterial and anticancer applications. AgNP's are highly in demand, because of its various applications in medicine, water treatment and catalysis. AgNP's based antimicrobial packaging is a promising form of active food packaging, which plays an important role in extending shelf-life of foods and reduce the risk of pathogens. Nanoparticles can be synthesized by physical methods, chemical methods and bio-assisted methods (5). The size and shape of AgNP's are controlled by the type of synthesis method. The chemical reduction of silver ions using sodium borohydride, hydrazine, ascorbic acid, tri sodium citrate and polyols were used in well established methods. Although chemical methods are effective, these methods may suffer from toxicity due to chemicals used and difficulty in removing them. Additionally chemical reagents are hazardous to the environment (6). 
Green synthesis is the application of certain ideologies that lessens or abolishes the use or production of hazardous chemicals. Biosynthesis of metal nanoparticles has been proposed as a simple, cost effective, high yield and environment friendly way of fabricating these materials (7). Various green synthesis methods include using plants, bacteria and fungi. Plants can be described as nano factories, which provide safe and beneficial way to the synthesis of metallic nanoparticles and there are possibilities for large scale production, apart from eco-friendly, the rate of production is faster in comparison to other biological models. The reducing capacity of plant depends on the presence of various polyphenols and other heterocyclic compounds (8). AgNPs using plant extracts like Murraya koenigii leaf (9), Mangosteen leaf (10), Mangifera indica leaf (11), Jatropha curcas (12), Cinnamomum zeylanicum leaf (13), Camellia sinensis (14), Aloe vera (15) etc. The advantage of using plant and fruit extract includes the formation of stable nanoparticles without molecular aggregation even if they are stored for a longer time.

Moringa oleifera (drumstick) is cultivated all most all over the country and its leaves and fruits are used as vegetables. Almost all parts of the plant have been utilized in traditional medicine properties. The leaves of plant have also been reported for its antitumor, hypotensive, cardioprotective, wound healing activities and use for eye diseases (16). First time synthesis of Ag nanoparticles were prepared by reducing the silver ions present in the solution of silver nitrate by the aqueous extract of $M$. oleifera leaf by (17). Tamarindus indica is a member of Fabaceae family and commonly known as 'Imli'. This is a very common fruit plant distributed throughout various regions of India. Tamarindus indica fruit is sweet and sour in taste and has tartaric acid, sugar and vitamins. In traditional medicine and food, it is used as the main ingredient in general. Synthesis of AgNP's using Tamarindus indica fruit extract without the addition of any external surfactant, capping agent or template was reported (18). The biologically synthesized nanoparticles were highly toxic against different pathogenic microorganisms at low concentrations. Silver ions have strong inhibitory and bactericidal effects as well as a broad spectrum of antimicrobial activities (19). Recent microbiological and chemical experiments implied that interaction of $\mathrm{Ag}+$ with thiol groups played an essential role in bacterial inactivation (20). It is revealed that bulk silver in an oxygen charged aqueous media catalyzes the complete destructive oxidation of microorganisms (21).

Silver nanoparticles are the metal of choice as they hold the promise to kill microbes effectively (22). The silver nanoparticles act on a broad range of target sites both extra-cellularly as well intra-cellularly. Microbes generally have a harder time developing resistance to silver than they do to antibiotics (23). Therefore, the aim of this work was to green synthesize, characterize and evaluate the antibacterial effects of silver nanoparticles.

\section{Materials And Methods}

\section{Materials}

$1 \mathrm{mM}$ silver Nitrate solution was prepared and the Moringa oleifera leaves, Tamarindus indica fruits were collected from the premises of College of Veterinary Science, Rajendranagar, Hyderabad, India.

\section{Preparation of plant extract}


The collected fresh leaves of Moringa oleifera are as shown in Fig.1. were washed in tap water to remove adhered dust particles. Then, it is dried in ambient temperature to remove residual moisture. After removal of moisture the dried leaves of Moringa oleifera were powdered in grinder. $20 \mathrm{~g}$ of finely powdered leaves of Moringa oleifera added to $100 \mathrm{ml}$ of double distilled water and boiled for 10 minutes. The extract cooled and filtered for further use. Similarly, 10 grams of tamarindus fruit (Fig.2.) was kept in $100 \mathrm{ml}$ of double distilled water, mixed well and boiled for 20 minutes. The extract obtained was filtered through Whatman No.1 filter paper and the filtrate was collected, stored till further use.

\section{Green Synthesis of Silver Nanoparticles using Moringa oleifera Leaf Extract and Tamarindus indica fruit extract}

For synthesis of silver nanoparticles different ratios of $1 \mathrm{mM}$ silver nitrate and $M$. oleifera leaf extract i.e., 95:5, 90:10 and 85: 15 was taken in to a conical flask and kept for $1 \mathrm{hr}$ at $25^{\circ} \mathrm{C}$ on magnetic stirrer. The bioreduction of $\mathrm{Ag}+$ to $\mathrm{Ag}^{0}$ with the action of moringa leaf extract is observed with the characteristic change in color from pale yellow to brown (Fig.3.) which may be attributed due to surface Plasmon resonance (SPR) of silver nanoparticles. Similarly, $100 \mathrm{ml}$ of $1 \mathrm{mM}$ silver nitrate solution was taken in conical flask and drop by drop Tamarindus indica fruit extract was added to it till the colour of the solution changes from light brown to chocolate brownish colour (Fig.4.).

\section{Characterization of Silver nanoparticles}

Characterization of silver nanoparticles will be done for the confirmation of nanoparticles formation, their size and shape.

\section{UV-Vis Spectral Analysis}

The silver nanoparticles were confirmed by measuring the wave length of reaction mixtures in the UV-vis spectrum of the Thermo fisher spectrophotometer at a resolution of $1 \mathrm{~nm}$ (from 300 to $600 \mathrm{~nm}$ ) in $2 \mathrm{ml}$ quartz cuvette with $1 \mathrm{~cm}$ path length.

\section{Zeta Potential Analysis}

The prepared sample was dispersed in deionised water followed by ultra-sonication. Afterwards the solution was filtered and centrifuged for $15 \mathrm{~min}$ at $25^{\circ} \mathrm{C}$ with $5000 \mathrm{rpm}$ and the supernatant was collected. The supernatant was diluted for 4 to 5 times and the particle distribution in liquid was studied in a computer-controlled particle size analyser (ZETA sizer Nano series, Malvern instrument Nano Zs).

\section{Bacterial culture and antibacterial activity}

The Staphylococcus aureus organism was isolated from 100 mastitis milk samples collected from different dairy farms in and around Hyderabad and confirmed by various biochemical tests (Table 1), catalase test, Gram staining. The pure culture was obtained from MTCC Chandigarh. The antibacterial sensitivity test was carried out against Staphylococcus aureus pure culture and isolates to check the 
efficacy of green synthesized AgNPs, by agar well diffusion method. Antimicrobial susceptibility of the isolates was done by the disc diffusion assay with Muller-Hinton (MH) agar and in accordance with CLSI recommendations. $\mathrm{MH}$ broth was inoculated with five colonies of the isolate and tubes were incubated at $37^{\circ} \mathrm{C}$ for 2-8 h until achieving a turbidity equivalent to 0.5 on the Mac Farland scale. After turbidity adjustment, a sterile swab was introduced, pressed against the tube well in order to remove any excess liquid and then seeded on the surface of a petri dish containing $\mathrm{MH}$ agar, for $S$. aureus rotating at least twice. Using sterile forceps 4 discs (Table 2) impregnated with antimicrobials and $50 \mu$ l of AgNP's of $M$. oleifera, Tamarindus indica, $\mathrm{AgNO}_{3}$, extracts and distilled water were placed at equal distances from each other on the surface of inoculated agar plate. Subsequently the plate was inverted and incubated at $37^{\circ} \mathrm{C}$ for $24 \mathrm{~h}$. Disc readings were performed after incubation and the diameter of inhibition halos was measured with the aid of a ruler. The interpretation was made as per the zone size interpretation chart provided by manufacturer of discs. The antibacterial activity against Staphylococcus aureus pure culture, isolates from mastitis milk was compared.

Table 1 Biochemical tests

\begin{tabular}{|l|l|c|}
\hline S. No & Tests & Typical reactions of S. aureus \\
\hline 1. & Indole & Negative \\
\hline 2. & Methyl Red & Positive \\
\hline 3. & Voges Proskauer & Positive \\
\hline 4. & Citrate (Simmons) & Positive \\
\hline 5. & Catalase & Positive \\
\hline 6. & Coagulase & Positive \\
\hline
\end{tabular}

Table 2 Antibiotics used in the antibiotic resistance/susceptible test

\begin{tabular}{|l|l|l|l|}
\hline S.No: & Antibiotics & Abbreviations & Concentration(ug/unit) \\
\hline 1. & Tetracycline & TE & 30 \\
\hline 2. & Ampicillin & AMP & 10 \\
\hline 3. & Ciprofloxacin & CIP & 5 \\
\hline 4. & Ceftriaxone & CTR & 30 \\
\hline
\end{tabular}

\section{Results}

CHARACTERIZATION OF SILVER NANOPARTICLES

\section{UV-Visible Spectroscopy}


The silver nanoparticles were characterized by UV-Visible spectroscopy, for confirmation of silver nanoparticles formation and the absorption spectrum of the brown silver nano solution prepared by using Moringa oleifera and Tamarindus indica showed a surface plasmon absorption band with maximum of $420 \mathrm{~nm}$ (Fig.5.) and $430 \mathrm{~nm}$ (Fig.6.) respectively, indicating the presence of silver nanoparticles.

\section{Zeta Potential and Size distribution by intensity}

Zeta potential measures the potential stability of the nanoparticles in the colloidal suspension. The zeta potential values of silver nanoparticles synthesized from Moringa oleifera and Tamarindus indica was $-12.3 \mathrm{mV}$ and $-15.5 \mathrm{mV}$ (Fig.7, 8.). These zeta potential values indicate good stability of silver nanoparticles synthesized. The size of the silver nanoparticles was $110.2 \mathrm{~nm}$ and $130.2 \mathrm{~nm}$ for AgNP's with Moringa oleifera and Tamarindus indica respectively (Fig.9,10.).

\section{Isolation and Identification of Staphylococcus aureus by cultural method}

Out of 100 total milk samples collected from different sources, 27 (27\%) milk samples were positive by traditional cultural methods. The isolation of Staphylococcus aureus was carried out by using BHI broth for enrichment and Mannitol salt agar media. The colonies were small size with yellow colour (Fig.11.). The presumptive colonies were subjected to gram staining (Fig.12.), biochemical tests (Fig.13.) and catalase test (Fig.14.) for confirmation.

\section{Antibacterial activity}

The antibacterial activity was recorded as the mean of zone of inhibition $(\mathrm{mm})$. The antibacterial activity of leaf extract of moringa and fruit extract of tamarind, pure silver nitrate solution, Ag nanoparticles with Moringa leaf and Tamarind fruit and antibiotics on Staphylococcus aureus pure culture and isolates was presented in the (Table 3 and Fig.15-18.).

Table 3 The antibacterial activity of silver nitrate solution, extracts, silver nanoparticles and antibiotics on pure cultures and isolates of Staphylococcus aureus from milk samples

\begin{tabular}{|c|l|c|c|}
\hline \multirow{2}{*}{ S.No } & \multirow{2}{*}{ Antibiotic/ material } & \multicolumn{2}{|c|}{ Zone of inhibition (mm) } \\
\cline { 3 - 4 } & & On pure cultures & On isolates (Mean \pm SE) \\
\hline 1 & AgNO 3 Solution & 14 & $13.00 \pm 0.25$ \\
\hline & Moringa oleifera leaf extract & 2 & $1.02 \pm 0.11$ \\
\hline 3 & Tamarindus indica fruit extract & 3 & $2.00 \pm 0.14$ \\
\hline 4 & Moringa oleifera AgNP's & 26 & $24.00 \pm 0.29$ \\
\hline 5 & Tamarindus indica AgNP's & 18 & $16.08 \pm 0.34$ \\
\hline 6 & tetracycline & 26 & $24.65 \pm 0.29$ \\
\hline 7 & ciprofloxacin & 10 & $8.15 \pm 0.28$ \\
\hline 8 & ampicillin & 6 & $4.29 \pm 0.27$ \\
\hline 9 & ceftriaxone & 32 & $28.29 \pm 0.43$ \\
\hline
\end{tabular}

\section{Discussion}




\section{Physical examination of silver nano solution}

In the present study when the Moringa oleifera leaf extract was added to the colorless silver nitrate solution, the colour changed from yellow to light brown and/or thick brown colour. The colour of silver nano solution prepared with Moringa oleifera leaf extract was dark brown colour (24). The change of colour from watery to yellowish brown and finally to green-black due to reduction of silver ion which indicated formation of silver nanoparticles using Moringa oleifera leaf extract (25). Change of colour from pale colour to yellowish brown (26), whereas observed change in colour from pale yellow to reddish brown (27) which confirmed the reduction of silver ions into nanoparticles using Moringa oleifera leaf extract. The colour of Tamarindus indica fruit extract was light brown and when it was added to the silver nitrate solution the color changed to dark brown color. The colour change of silver nitrate solution into brown to dark brown color indicates that silver nanoparticles were formed (28). The reason for the brown colour is due to the extraction of surface Plasmon vibrations in the silver nanoparticles prepared by using Tamarindus indica fruit shell (29). Yellowish brown color, reported for the Ag nano solution prepared by Tamarindus indica fruit extract (30).

\section{Characterization of silver nanoparticles}

\section{UV-Visible Spectroscopy}

The structural characterization of silver nanoparticles was characterized by UV-Visible spectroscopy. The formation of AgNP's will be confirmed by UV-Vis spectral study, which is an authentic technique to monitor the progress of the reaction during the reduction of silver ions. The absorption spectrum of the brown silver nano solution prepared by using Moringa oleifera and Tamarindus indica showed a surface plasmon absorption band with maximum of $420 \mathrm{~nm}, 430 \mathrm{~nm}$ indicating the presence of silver nanoparticles. The occurance of peak at $420 \mathrm{~nm}, 430 \mathrm{~nm}$ is due to the phenomenon of surface plasmon resonance, which occurs due to the excitation of the surface plasmon present on the outer surface of the silver nanoparticles which gets excited to the applied electro-magnetic field (31). The UV absorption peak of silver nanoparticles range from $400 \mathrm{~nm}$ to $450 \mathrm{~nm}$ (32). The peaks obtained in this study for nanoparticles were within the range, clearly indicating the formation of silver nanoparticles. The UV-Vis spectral peak of $420 \mathrm{~nm}$ (33), $430 \mathrm{~nm}$ (34), $460.8 \mathrm{~nm}$ (35), $450 \mathrm{~nm}$ (24) was reported for the AgNP's prepared by using Moringa oleifera leaf extract, where some was lower, higher and similar to the peak observed in the present study.

Higher UV-Vis spectral peak at $432 \mathrm{~nm}$ for the AgNP's prepared by using Tamarindus indica leaf extract were reported (28), UV-Vis spectral peak at $450 \mathrm{~nm}$ for the AgNP's prepared by using Tamarindus indica fruit shell extract, which was higher than the present study $(430 \mathrm{~nm})$ was reported (29). Very high UVVisible spectra peak (491 nm) was observed for the AgNP's prepared by using $T$. indica leaf extract (36). Very low UV-Vis spectral peak at $348 \mathrm{~nm}$ using tamarind fruit extract compared to the peak $(430 \mathrm{~nm})$ observed in the present study (37).

\section{Zeta Potential}


Zeta potential measures the potential stability of the nanoparticles in the colloidal suspension. The zeta potential of silver nanoparticles synthesized from Moringa oleifera leaf extract and Tamarindus indica fruit extract was $-12.3 \mathrm{mV}$ and $-15.5 \mathrm{mV}$ respectively. This zeta potential value indicates good stability of silver nanoparticles synthesized. The zeta potential to know the stability of AgNP's synthesized by using Ocimum sanctum leaf extract was - $55.0 \mathrm{mv}$ (38), whereas, the zeta potential value is $-47.1 \mathrm{mV}$ and -43 $\mathrm{mV}$ at $\mathrm{pH} 5.5$ for the silver nanoparticles synthesized by using extract of callus cultures of pumpkin (Cucurbita maxima) (39). The zeta potential value in the range of -10 to $-30 \mathrm{mV}$ for the gold nanoparticles synthesized by using different plant extracts was reported (40).

\section{Antibacterial activity and comparison against Staphylococcus aureus}

The antibacterial activity was recorded as the mean of zone of inhibition $(\mathrm{mm})$. Distilled water has been taken as control which showed no zone of inhibition against Staphylococcus aureus. The mean of ZOI of tetracycline, ciprofloxacin, ampicillin, ceftriaxone, AgNP's with Moringa and AgNP'S with tamarind were $26 \mathrm{~mm}, 10 \mathrm{~mm}, 6 \mathrm{~mm}, 32 \mathrm{~mm}, 26 \mathrm{~mm}$ and $18 \mathrm{~mm}$ respectively against Staphylococcus aureus pure cultures, whereas mean of ZOI against Staphylococcus aureus isolates from milk samples was $24.65 \pm 0.29 \mathrm{~mm}, 8.15 \pm 0.28 \mathrm{~mm}, 4.29 \pm 0.27 \mathrm{~mm}, 28.29 \pm 0.43 \mathrm{~mm}, 24.00 \pm 0.29 \mathrm{~mm}$ and $16.08 \pm 0.34 \mathrm{~mm}$ respectively. The mean of ZOI with Moringa leaf extract was 2 and $1.02 \pm 0.11 \mathrm{~mm}$ respectively for pure culture and isolates from milk samples of Staphylococcus aureus. On contrary to the present findings $(34,27)$ reported no zone of inhibition against Staphylococcus aureus with Moringa leaf extract. The ZOI as $5.67 \pm 1.52 \mathrm{~mm}, 13.00 \pm 2.64 \mathrm{~mm}$ for Moringa oleifera crude leaf extract at concentration of 50 and 100 $\mu \mathrm{g} /$ disc respectively which was higher than the present study was reported (41). The mean of ZOI of pure $\mathrm{AgNO}_{3}$ solution was 14 and $13.00 \pm 0.25 \mathrm{~mm}$ respectively for pure culture and isolates of Staphylococcus aureus from milk samples. Very low antibacterial activity was reported for $\mathrm{AgNO}_{3}$ solution against Staphylococcus aureus with zone of inhibition of $2 \mathrm{~mm}$ (27). Slightly higher ZOI (15 mm) than the present study was reported for $\mathrm{AgNO}_{3}$ solution (18). The mean of $\mathrm{ZOI}$ of $\mathrm{Ag}$ nanoparticles prepared using Moringa oleifera leaf extract was 26 and $24.00 \pm 0.29 \mathrm{~mm}$ respectively for pure culture and isolates from milk samples in the present study. This zone of inhibition for silver nanoparticles was higher compared to $\mathrm{AgNO}_{3}$ solution, whereas similar zone of inhibition (2 mm) against Staphylococcus aureus for both silver nitrate solution as well as silver nanoparticles was reported (38).) The ZOI against Staphylococcus aureus as $15 \mathrm{~mm}$ by using AgNP's synthesised by using Moringa oleifera leaf extract, which was less than the ZOI $(24.00 \pm 0.29 \mathrm{~mm})$ observed in the present study was reported $(17,34)$. The ZOI against Staphylococcus aureus as $21.67 \mathrm{~mm}$ and $12.60 \mathrm{~mm}$ for AgNP's prepared by using Moringa oleifera leaf extract, which was less than mean of ZOI observed in the present study was reported (41-42). The ZOI against Staphylococcus aureus increased as the concentration of AgNP's increased and reported the ZOI of $15,18,20 \mathrm{~mm}$ at 25,50, 100 microliters AgNP's concentration respectively (33). The mean of inhibition zone with Tamarindus indica fruit extract was $3 \mathrm{~mm}$ and $2.00 \pm 0.14 \mathrm{~mm}$ respectively for pure culture and isolates from milk samples against Staphylococcus aureus. The antibacterial activity of tamarindus fruit extract might be due to Tartaric acid present in the fruit, which increases the acidity that effects the bacterial growth (28). No ZOI for Staphylococcus aureus (18), whereas (28) observed minor ZOI with 
tamarind fruit extract. The mean of zone of inhibition of AgNP's prepared using tamarind fruit extract against Staphylococcus aureus was $18 \mathrm{~mm}$ and 16.08 $\pm 0.34 \mathrm{~mm}$ respectively for pure cultures and isolates from milk samples, which was similar to the value reported by (18), whereas slightly less ZOI (14 $\mathrm{mm}$ ) was reported by (28). The ZOI of tetracycline and ampicillin as $18 \mathrm{~mm}$ and $25 \mathrm{~mm}$ respectively on Staphylococcus aureus, which was lower than the value for tetracycline and higher than the value for ampicillin in the present study was reported (43). The ZOI of ciprofloxacin as $21 \pm 1.41 \mathrm{~mm}$ on Staphylococcus aureus, which was higher than the value in the present study was reported (44). The mean of ZOI against Staphylococcus aureus with antibiotics used in this study was high with ceftriaxone $(28.29 \pm 0.43 \mathrm{~mm})$ followed by tetracycline $(24.65 \pm 0.29 \mathrm{~mm})$ and less with ciprofloxacin $(8.15 \pm 0.28 \mathrm{~mm})$ and ampicillin $(4.29 \pm 0.27 \mathrm{~mm})$. ZOI of ampicillin as $15.03 \pm 0.54 \mathrm{~mm}$ against Staphylococcus aureus was reported (45) which was slightly near to the ZOI value of $\mathrm{AgNO}_{3}$ solution. The study on AgNP's prepared by using Moringa oleifera, Tamarindus indica and comparing their antibacterial efficacy with antibiotics was less, but there is lot of scope for future study.

\section{Conclusion}

The conclusion of the present study indicates that the AgNP's prepared with Moringa oleifera and Tamarindus indica was almost equally efficient against Staphylococcus aureus and the AgNP's antibacterial activity is almost comparable with most of the antibiotics studied in this work.

\section{Declarations}

\section{Conflict of interest}

The authors declare that there are no conflicts of interests.

\section{Acknowledgement}

The authors are very much thankful to the funding agency i.e., IG-NAHEP for providing the necessary chemicals and reagents to carry out the present research.

\section{References}

1. Colvin V L, Schlamp M C and Alivisatos A P. 1994. Light-emitting diodes made from cadmium selenide nanocrystals and a semiconducting polymer. Nature 370(6488): 354-357. https://doi.org/10.1038/370354a0

2. Leela $A$ and Vivekanandan M. 2008. Tapping the unexploited plant resources for the synthesis of silver nanoparticles. African Journal of Biotechnology 7(17): 3162-3165. http://www.academicjournals.org/AJB

3. Daniel M C and Astruc D. 2004. Gold nanoparticles: assembly, supramolecular chemistry, quantumsize-related properties, and applications toward biology, catalysis, and nanotechnology. Chemical 
reviews 104(1): 293-346. https://doi.org/10.1021/cr030698+

4. Ghosh S, Patil S, Ahire M, Kitture R, Kale S, Pardesi K and Chopade B A. 2012. Synthesis of silver nanoparticles using Dioscorea bulbifera tuber extract and evaluation of its synergistic potential in combination with antimicrobial agents. International journal of nanomedicine 7: 483-496. https://doi.org/10.2147/ijn.s24793

5. Dhand C, Dwivedi N, Loh X J, Ying A N J, Verma N K, Beuerman R W and Ramakrishna S. 2015. Methods and strategies for the synthesis of diverse nanoparticles and their applications: a comprehensive overview. Rsc Advances 5(127): 105003-105037. https://doi.org/10.1039/C5RA19388E

6. Nabikhan A, Kandasamy K, Raj A and Alikunhi N M. 2010. Synthesis of antimicrobial silver nanoparticles by callus and leaf extracts from saltmarsh plant, Sesuvium portulacastrum L. Colloids and surfaces B: Biointerfaces 79(2): 488-493. https://doi.org/10.1016/j.colsurfb.2010.05.018

7. Zhang Y, Cheng X, Zhang Y, Xue X and Fu Y. 2013. Biosynthesis of silver nanoparticles at room temperature using aqueous aloe leaf extract and antibacterial properties. Colloids and Surfaces A: Physicochemical and Engineering Aspects 423: 63-68. https://dx.doi.org/10.7717\%2Fpeerj.2589

8. Nair R, Varghese S H, Nair B G, Maekawa T, Yoshida Y and Kumar D S. 2010. Nanoparticulate material delivery to plants. Plant science 179(3): 154-163.

http://dx.doi.org/10.1016/j.plantsci.2010.04.012

9. Philip D, Unni C, Aromal S A and Vidhu V K. 2011. Murraya koenigii leaf-assisted rapid green synthesis of silver and gold nanoparticles. Spectrochimica Acta Part A: Molecular and Biomolecular Spectroscopy 78(2): 899-904. https://doi.org/10.1016/j.saa.2010.12.060

10. Veerasamy R, Xin T Z, Gunasagaran S, Xiang T F W, Yang E F C, Jeyakumar N and Dhanaraj S A. 2011. Biosynthesis of silver nanoparticles using mangosteen leaf extract and evaluation of their antimicrobial activities. Journal of saudi chemical society 15(2): 113-120. https://doi.org/10.1016/j.jscs.2010.06.004

11. Kaviyarasu K, Manikandan E, Paulraj P, Mohamed S B and Kennedy J. 2014. One dimensional wellaligned CdO nanocrystal by solvothermal method. Journal of alloys and compounds 593: 67-70. http://dx.doi.org/10.1016/j.jallcom.2014.01.071

12. Bar H, Bhui D K, Sahoo G P, Sarkar P, De S P and Misra A. 2009. Green synthesis of silver nanoparticles using latex of Jatropha curcas. Colloids and surfaces A: Physicochemical and engineering aspects 339(1-3): 134-139. http://dx.doi.org/10.1016\%2Fj.colsurfa.2009.02.008

13. Smitha S L, Philip D and Gopchandran K G. 2009. Green synthesis of gold nanoparticles using Cinnamomum zeylanicum leaf broth. Spectrochimica Acta Part A: Molecular and Biomolecular Spectroscopy 74(3): 735-739. https://doi.org/10.1016/j.saa.2009.08.007

14. Vilchis-Nestor A R, Sánchez-Mendieta V, Camacho-López M A, Gómez-Espinosa R M, Camacho-López M A and Arenas-Alatorre J A. 2008. Solventless synthesis and optical properties of Au and Ag nanoparticles using Camellia sinensis extract. Materials letters 62(17-18): 3103-3105. 
15. Chandran S P, Chaudhary M, Pasricha R, Ahmad A and Sastry M. 2006. Synthesis of gold nanotriangles and silver nanoparticles using Aloe vera plant extract. Biotechnology progress 22(2): 577-583. https://doi.org/10.1021/bp0501423

16. Rathi B, Bodhankar S, Deheti A M. 2006. Evaluation of aqueous leaves extract of M. oleifera Lin for wound healing in albino rats. Ind J of Exp Bio 44: 898-901. PMID: 17205710

17. Prasad T N V K V and Elumalai E K. 2011. Biofabrication of Ag nanoparticles using Moringa oleifera leaf extract and their antimicrobial activity. Asian Pacific Journal of Tropical Biomedicine 1(6): 439442. https://dx.doi.org/10.1016\%2FS2221-1691(11)60096-8

18. Jayaprakash N, Vijaya J J, Kaviyarasu K, Kombaiah K, Kennedy L J, Ramalingam R J and AlLohedan H A. 2017. Green synthesis of Ag nanoparticles using Tamarind fruit extract for the antibacterial studies. Journal of Photochemistry and Photobiology B: Biology 169: 178-185.

19. Berger T J, Spadaro J A, Chapin S E and Becker R O. 1976. Electrically generated silver ions: quantitative effects on bacterial and mammalian cells. Antimicrobial agents and chemotherapy 9(2): 357-358. https://dx.doi.org/10.1128\%2Faac.9.2.357

20. Liau S Y, Read D C, Pugh W J, Furr J R and Russell A D. 1997. Interaction of silver nitrate with readily identifiable groups: relationship to the antibacterial action of silver ions. Letters in applied microbiology 25(4): 279-283. https://doi.org/10.1046/j.1472-765x.1997.00219.x

21. Davies R L and Etris S F. 1997. The development and functions of silver in water purification and disease control. Catalysis Today 36(1): 107-114. https://doi.org/10.1016/S0920-5861(96)00203-9

22. Sondi I and Salopek-Sondi B. 2004. Silver nanoparticles as antimicrobial agent: a case study on $E$. coli as a model for Gram-negative bacteria. Journal of colloid and interface science 275(1): 177-182. https://doi.org/10.1016/j.jcis.2004.02.012

23. Baker C, Pradhan A, Pakstis L, Pochan D J and Shah S I. 2005. Synthesis and antibacterial properties of silver nanoparticles. Journal of nanoscience and nanotechnology 5(2): 244-249. https://doi.org/10.1166/jnn.2005.034

24. Moodley J S, Krishna S B N, Pillay K and Govender P. 2018. Green synthesis of silver nanoparticles from Moringa oleifera leaf extracts and its antimicrobial potential. Advances in Natural Sciences: Nanoscience and Nanotechnology 9(1): 015011. http://doi.org/10.1088/2043-6254/aaabb2

25. Shivashankar M and Sisodia G. 2012. Biosynthesis of silver nanoparticles obtained from plant extracts of Moringa oleifera. Int. J. Life Sci. Biotechnol. Pharm. Res 1: 180-185.

26. Sathyavathi R, Krishna M and Rao D N. 2011. Biosynthesis of silver nanoparticles using Moringa oleifera leaf extract and its application to optical limiting. Journal of nanoscience and nanotechnology 11(3): 2031-2035. https://doi.org/10.1166/jnn.2011.3581

27. Shilpashree Mayachar K, Nandini N and Alaknanda J A. 2018. Research Journal of Chemical and Environmental Sciences 6 (5): 48-57.

28. Verma K D, Hasan S H and Banik R M. 2015. Swift green synthesis of silver nanoparticles using aqueous extract of Tamarindus indica leaves and evaluation of its antimicrobial potential. Int. J. Innov. Res. Sci. Eng. Technol 4(11): 11182- 11190. 
29. Gomathi A C, Rajarathinam S X and Sadiq A M. 2019. Green Synthesis and Characterization of Silver Nanoparticles using aqueous extract of Tamarindus indica fruit Shell. Journal of Emerging Technologies and Innovative Research 6(5): 415-424.

30. Muthu and Suganya. 2018. Green Synthesis of Ag nanoparticles using tamarind fruit extract. International Journal of Pure and Applied Mathematics 119(12): 3161-3170.

31. Pradhan S. 2015. Comparative analysis of Silver Nanoparticles prepared from Different Plant extracts (Hibiscus rosasinensis, Moringa oleifera, Acorus calamus, Cucurbita maxima, Azadirachta indica) through green synthesis method, Master's degree in Life Science. National Institute of Technology, Rourkela.

32. Ramteke C, Chakrabarti T, Sarangi B K and Pandey R A. 2013. Synthesis of silver nanoparticles from the aqueous extract of leaves of Ocimum sanctum for enhanced antibacterial activity. Journal of chemistry 2013.

33. Narwade B, Prasad N, Lokhande S M, Madavi A B and Sahoo A K. 2018. Extracellular Biosynthesis of Silver Nanoparticles using Moringa oleifera Leaves Extract and its Antimicrobial Efficacy in Packaging Materials. Research Journal of Life Sciences, Bioinformatics, Pharmaceutical and Chemical Science 4(2): 188-202.

34. Al-Kalifawi E J. 2016. Green Synthesis of Silver Nanoparticles using Leaf Extract of Al-Rawag tree (Moringa oleifera Lamarck) Cultivated in Iraq and Efficacy the Antimicrobial activity. Mesopotamia Environmental Journal (Special Issue A): 39-48.

35. Ilavarashi P, Rani N, Velusamy R, Raja M J and Ponnudurai G. 2019. In-vitro anthelmintic evaluation of synthesized silver nanoparticles of Moringa oleifera seeds against strongyle nematode of small ruminants. Journal of Pharmacognosy and Phytochemistry 8(6): 2116-2121.

36. Le N T T, Trinh B T, Nguyen D H, Tran L D, Luu C H and Hoang Thi T T. 2021. The physicochemical and antifungal properties of eco-friendly silver nanoparticles synthesized by Psidium guajava leaf extract in the comparison with Tamarindus indica. Journal of Cluster Science 32: 601-611.

37. Renuka R, Thilagavathi T, Renuka Devi K.2017. Synthesis and characterization of fruit mediated silver nanoparticles using Tamarindus indica fruit extract. International Journal of Scientific and Engineering Research 8(10).

38. Rao Y S, Kotakadi V S, Prasad T N V K V, Reddy A V and Gopal D S. 2013. Green synthesis and spectral characterization of silver nanoparticles from Lakshmi tulasi (Ocimum sanctum) leaf extract. Spectrochimica Acta Part A: Molecular and Biomolecular Spectroscopy 103: 156-159. https://doi.org/10.1016/j.saa.2012.11.028

39. Iyer R I and Panda T. 2018. Biosynthesis of gold and silver nanoparticles using extracts of callus cultures of pumpkin (Cucurbita maxima). Journal of nanoscience and nanotechnology 18(8): 53415353. https://doi.org/10.1166/jnn.2018.15378

40. Elia P, Zach R, Hazan S, Kolusheva S, Porat Z E and Zeiri Y. 2014. Green synthesis of gold nanoparticles using plant extracts as reducing agents. International journal of nanomedicine 9 : 4007-4021. https://dx.doi.org/10.2147\%2FIJN.S57343 
41. Islam A, Mandal C and Habib A. 2021. Antibacterial potential of synthesized silver nanoparticles from leaf extract of Moringa oleifera. J Adv Biotechnol Exp Ther 4: 67.

42. Das S, Parida U K and Bindhani B K. 2013. Green biosynthesis of silver nanoparticles using Moringa oleifera L. leaf. Int J Nanotechnol Appl 3(2): 51-62.

43. Sebiomo A, Awofodu A D, Awosanya A O, Awotona F E and Ajayi A J. 2011. Comparative studies of antibacterial effect of some antibiotics and ginger (Zingiber officinale) on two pathogenic bacteria. Journal of Microbiology and Antimicrobials 3(1): 18-22.

44. Singh R, Ray P, Das A and Sharma M. 2010. Penetration of antibiotics through Staphylococcus aureus and Staphylococcus epidermidis biofilms. Journal of antimicrobial chemotherapy 65(9): 1955-1958. https://doi.org/10.1093/jac/dkq257

45. Priyadarshini S, Sulava S, Bhol R and Jena S. 2019. Green synthesis of silver nanoparticles using Azadirachta indica and Ocimum sanctum leaf extract. Current Science 117(8): 1300-1307. http://dx.doi.org/10.18520/cs/v117/i8/1300-1307

\section{Figures}

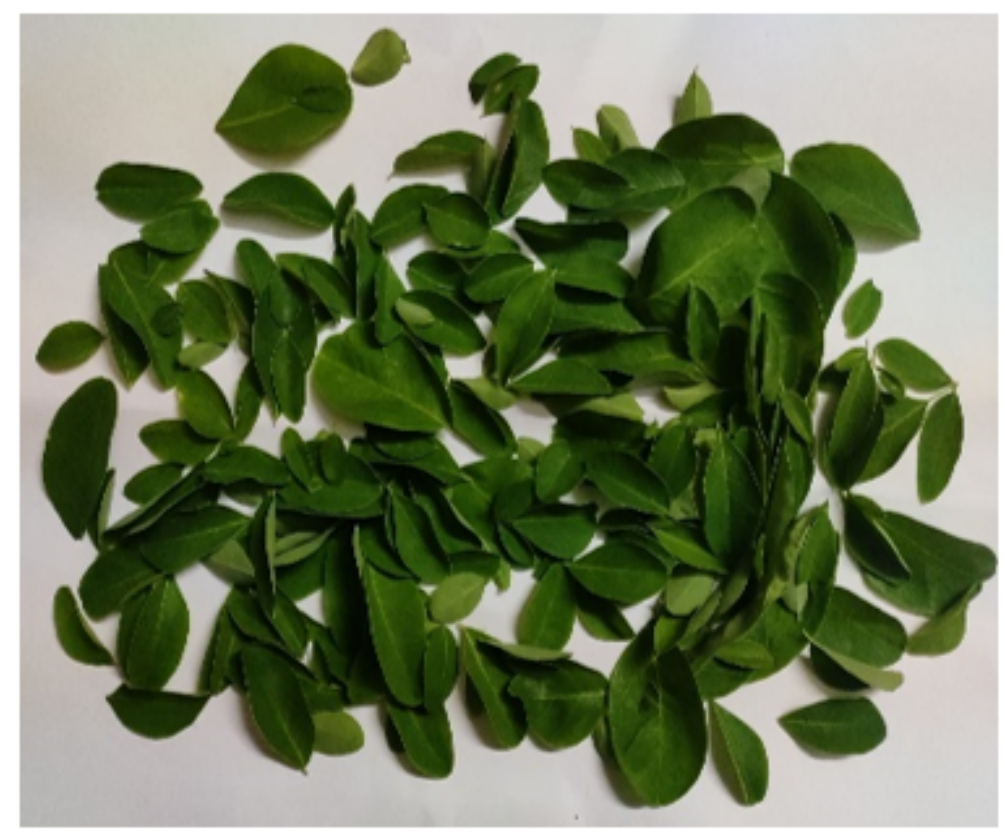

\section{Figure 1}

Moringa oleifera fresh leaves 


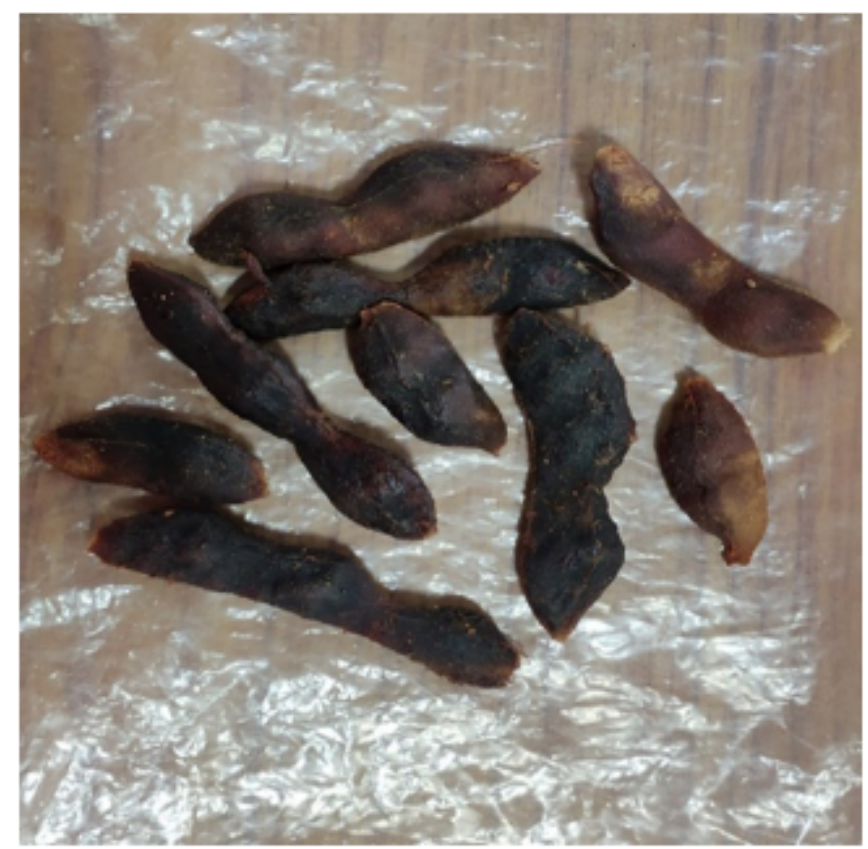

Figure 2

Tamarindus indica fruit

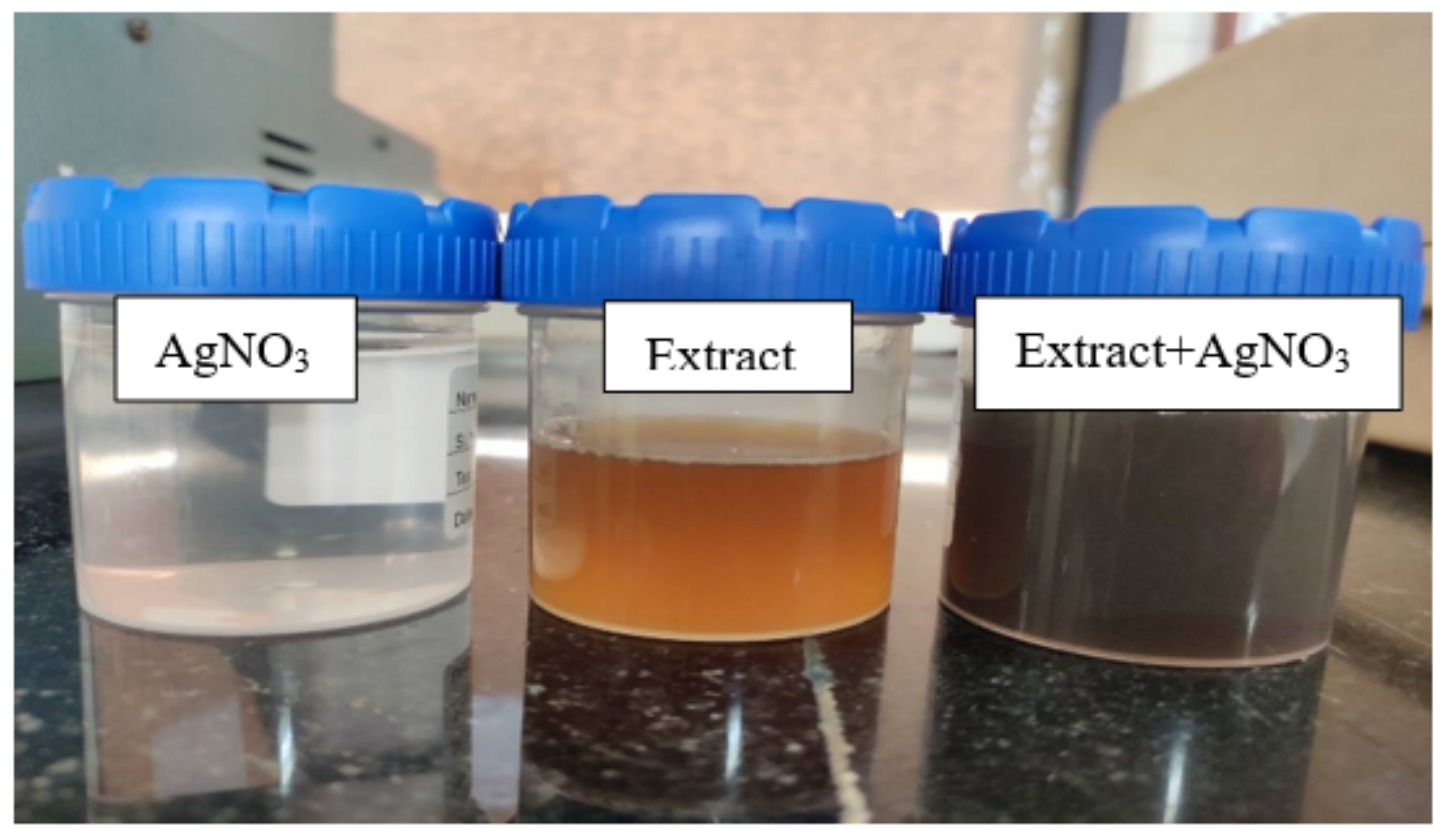

Figure 3

Silver nano solution with Moringa before and after addition of AgNO3 


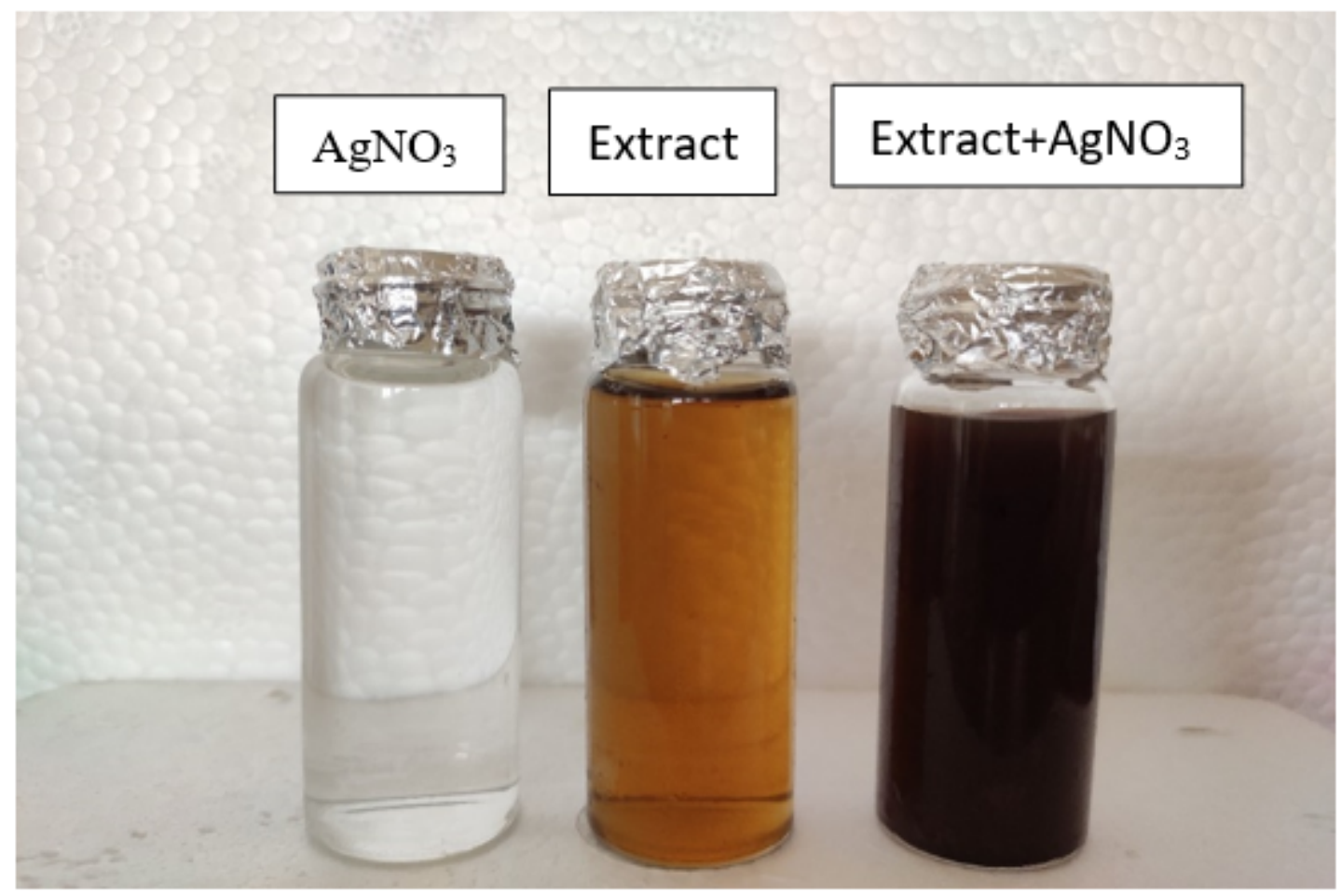

\section{Figure 4}

Silver nano solution with Tamarind before and after addition of AgNO3

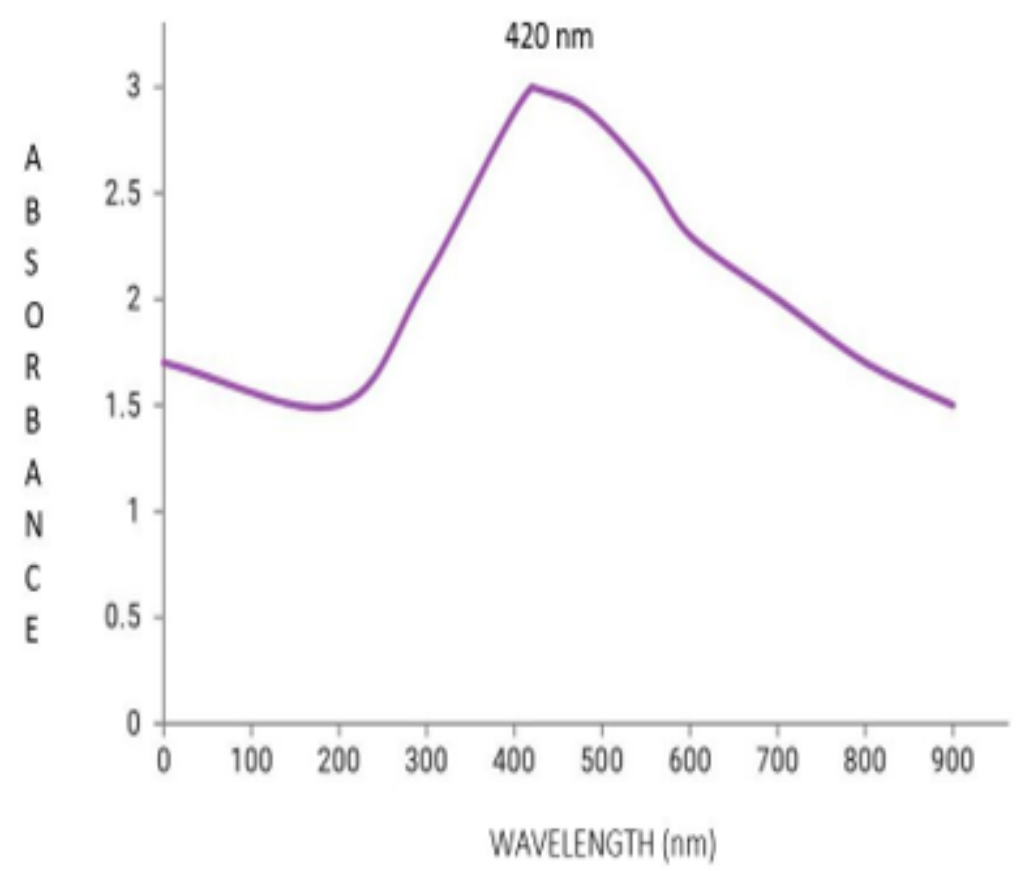

Figure 5

UV-Visible absorption peak of $420 \mathrm{~nm}$ for AgNP's prepared with Moringa oleifera leaf extract 


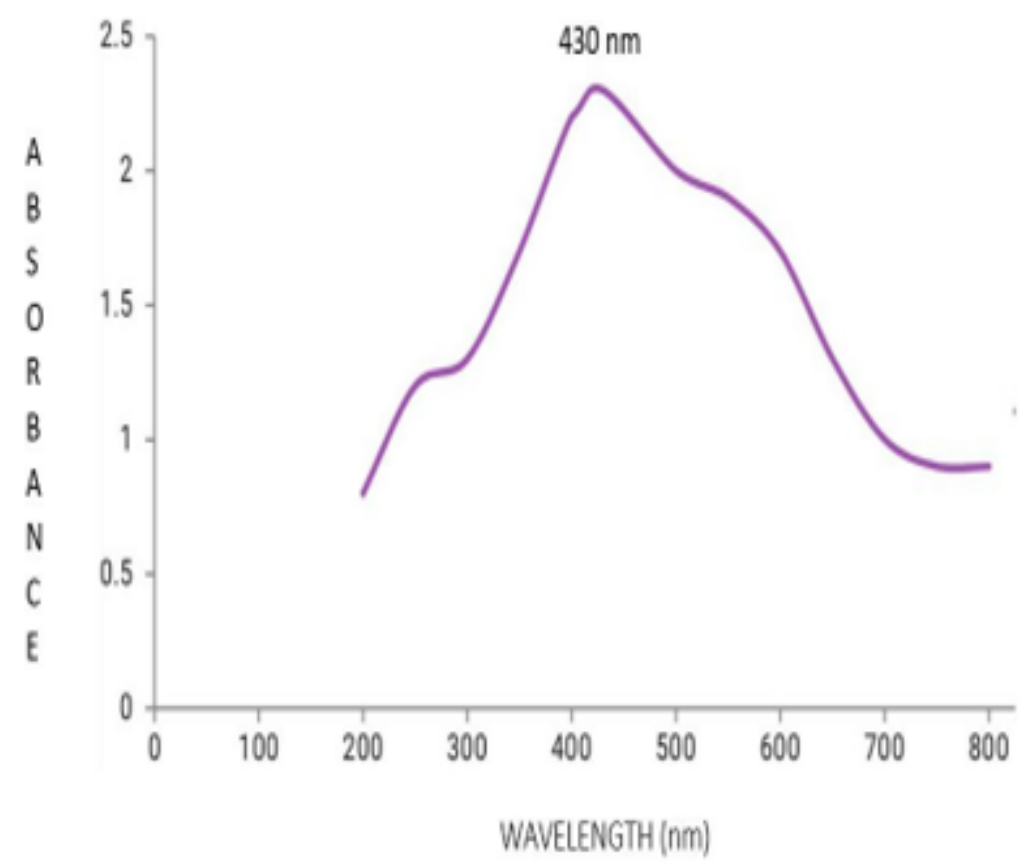

Figure 6

UV-Visible absorption peak of $430 \mathrm{~nm}$ for AgNP's prepared with Tamarindus indica fruit extract

\begin{tabular}{|c|c|c|c|c|c|}
\hline \multicolumn{6}{|l|}{ Results } \\
\hline & & & Mean $(m V)$ & Area (\%) & St $\operatorname{Dev}(\mathrm{mV})$ \\
\hline Zeta Potential $(m \mathrm{~m})$ : & -12.3 & Peak 1: & -12.3 & 100.0 & 4.60 \\
\hline Zeta Deviation $(\mathrm{mV})$ : & 4.60 & Peak 2: & 000 & 0.0 & 0.00 \\
\hline Conductivity $(\mathrm{mS} / \mathrm{cm})$ : & 0.564 & Peak 3: & 0.00 & 0.0 & 0.00 \\
\hline Result quality: & See re & y report & & & \\
\hline
\end{tabular}

Zeta Potential Distribusion

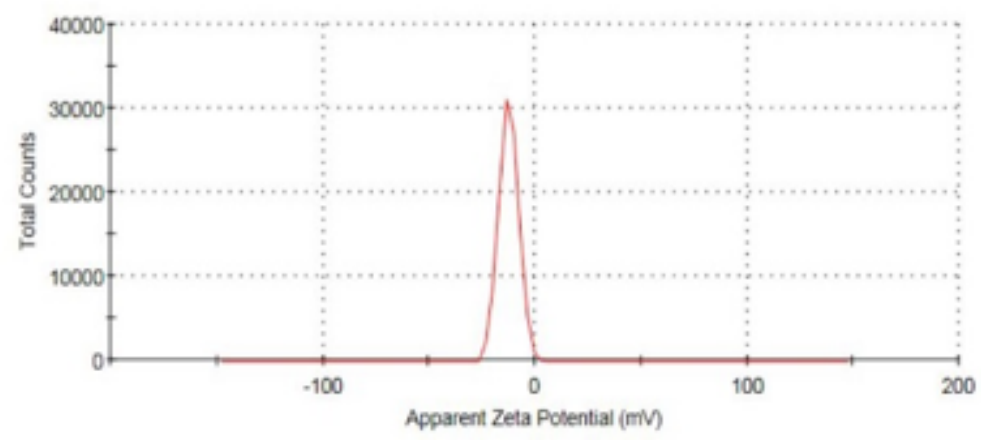

Figure 7

Zeta potential distribution of AgNP's prepared with Moringa oleifera leaf extract 


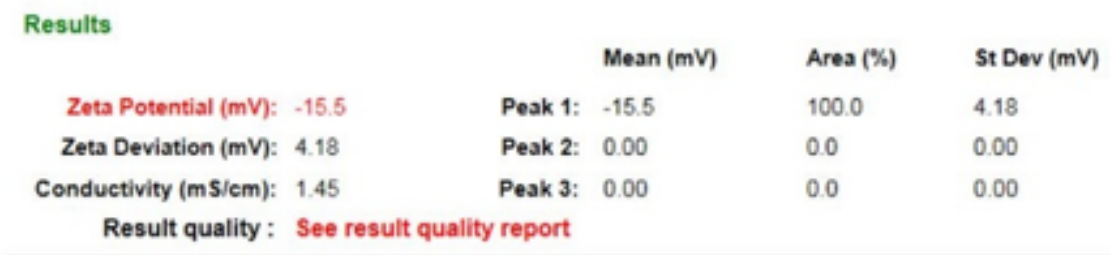

Zeta Potential Distribution

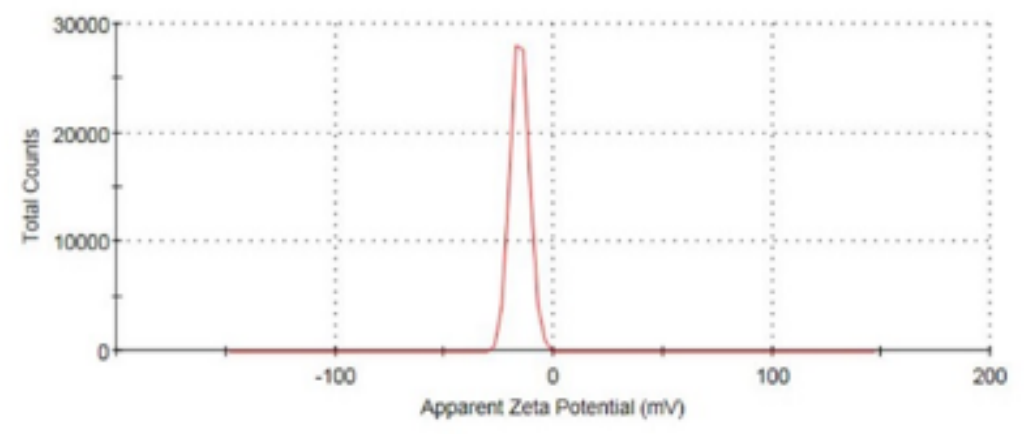

\section{Figure 8}

Zeta potential distribution of AgNP's prepared with Tamarindus indica fruit extract

\begin{tabular}{|c|c|c|c|c|c|}
\hline & & & Size (d.nm): & $\%$ Intensity: & St Dev (d.n... \\
\hline Z-Average (d.nm): & 110.2 & Peak 1: & 134.2 & 100.0 & 66.73 \\
\hline Pdl: & 0.240 & Peak 2: & 0.000 & 0.0 & 0.000 \\
\hline Intercept: & 0.964 & Peak 3: & 0.000 & 0.0 & 0.000 \\
\hline Result quality : & Good & & & & \\
\hline
\end{tabular}

Size Distribution by Intensity

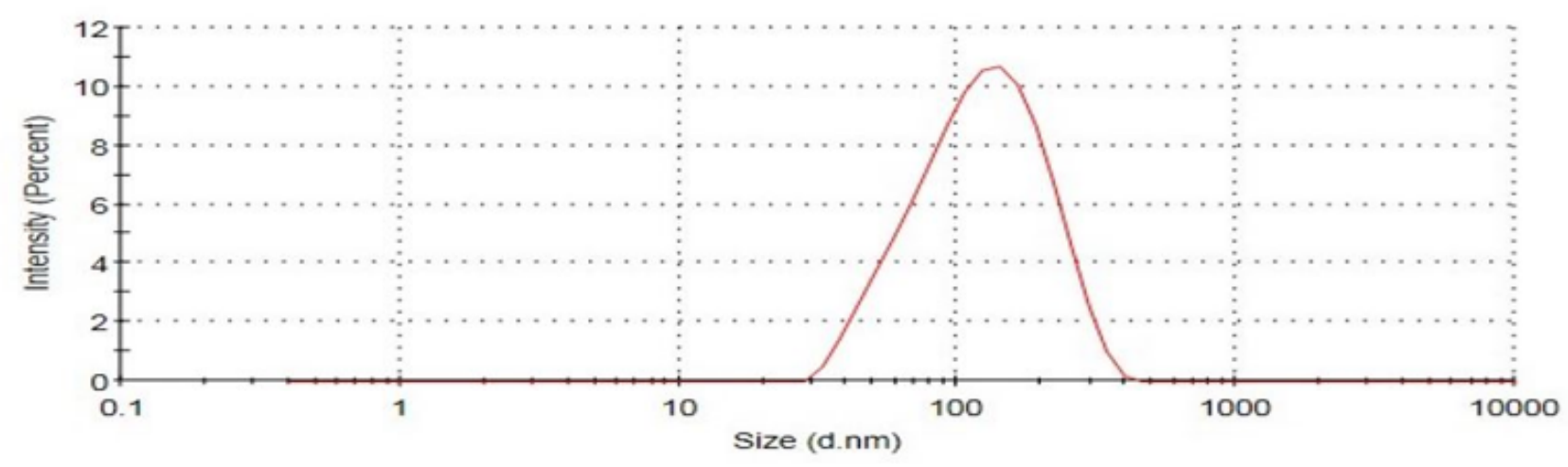

Figure 9

Size distribution by intensity of AgNP's prepared with Moringa oleifera leaf extract 


\begin{tabular}{|c|c|c|c|c|c|}
\hline & & & Size (d.nm): & $\%$ Intensity: & St Dev (d.n... \\
\hline Z-Average (d.nm): & 130.2 & Peak 1: & 149.1 & 100.0 & 56.88 \\
\hline PdI: & 0.193 & Peak 2: & 0.000 & 0.0 & 0.000 \\
\hline Intercept: & 0.956 & Peak 3: & 0.000 & 0.0 & 0.000 \\
\hline
\end{tabular}

Size Distribution by Intensity

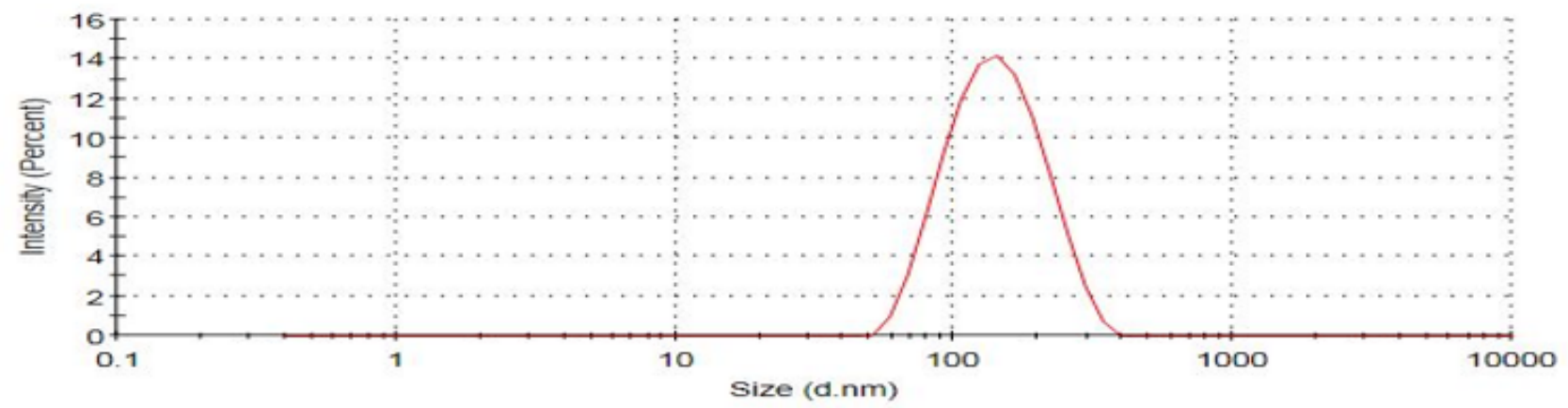

Figure 10

Size distribution by intensity of AgNP's prepared with Tamarindus indica fruit extract

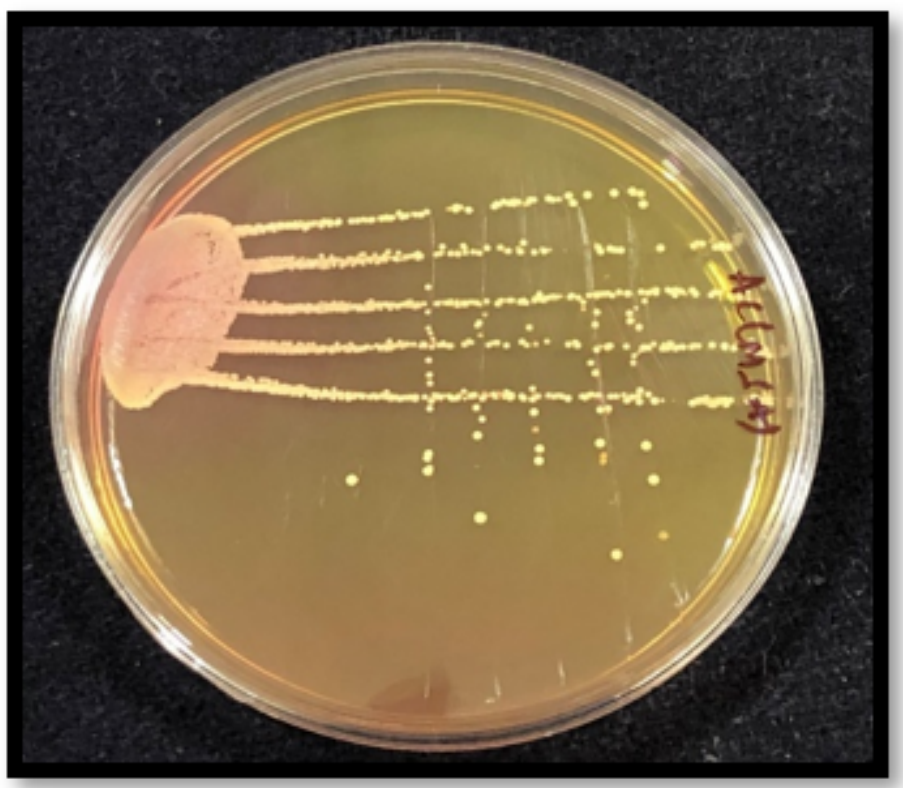

Figure 11

Plate showing the growth of Staphylococcus aureus colonies on MSA media 


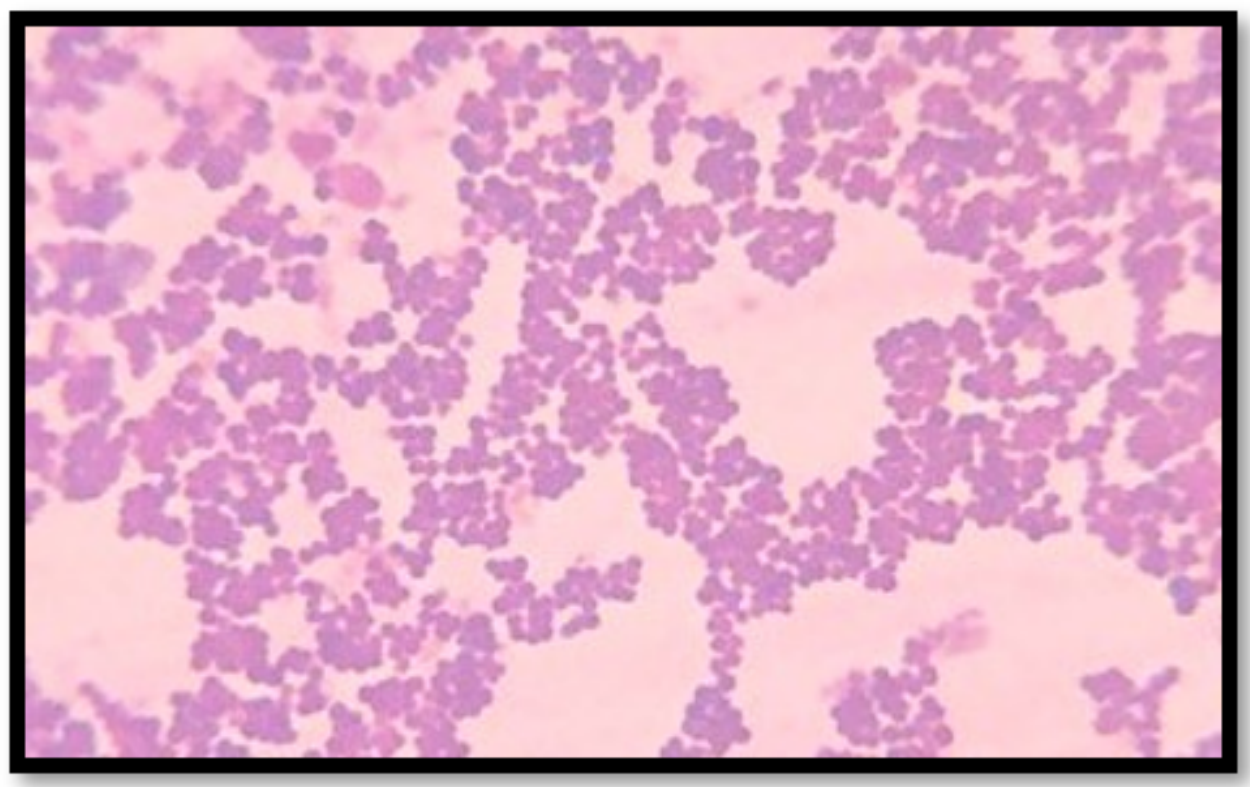

Figure 12

Gram staining for Staphylococcus aureus

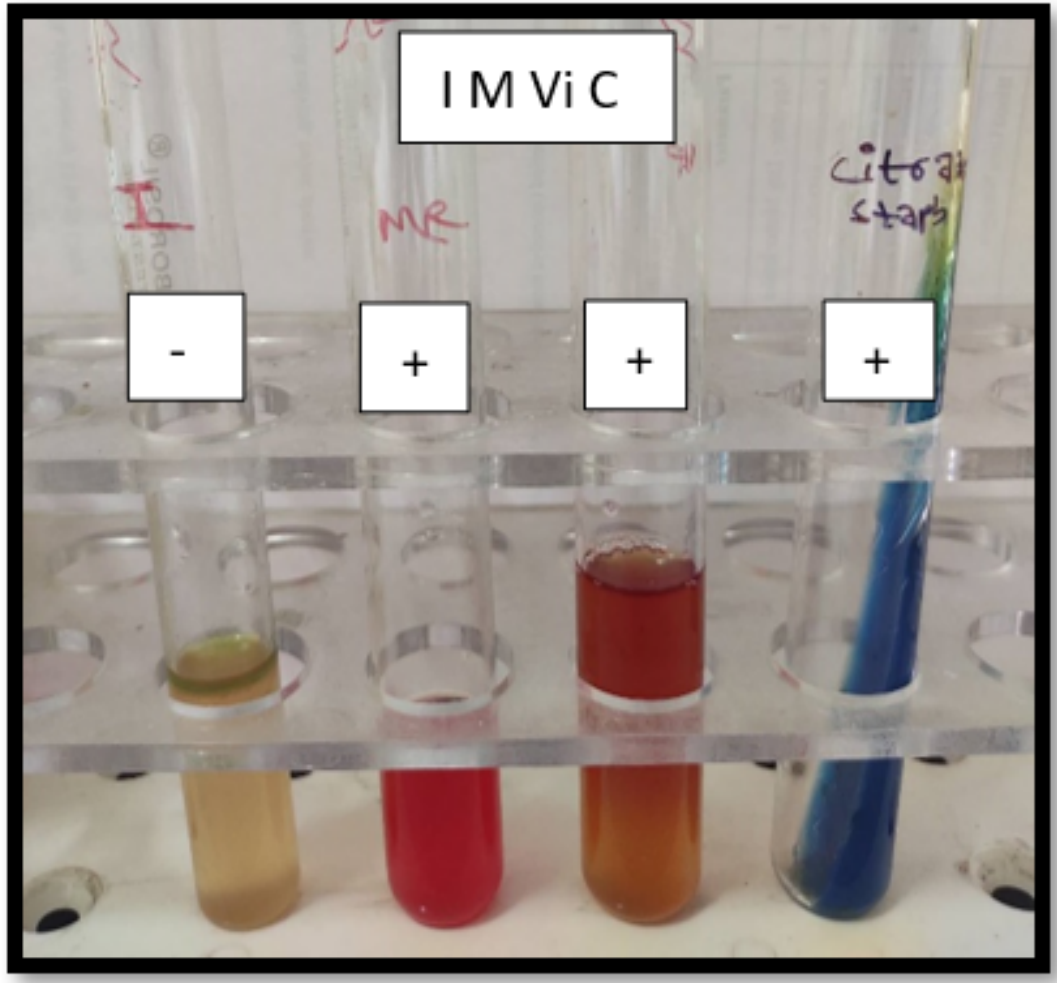

Figure 13

Results of biochemical tests and catalase test for Staphylococcus aureus 


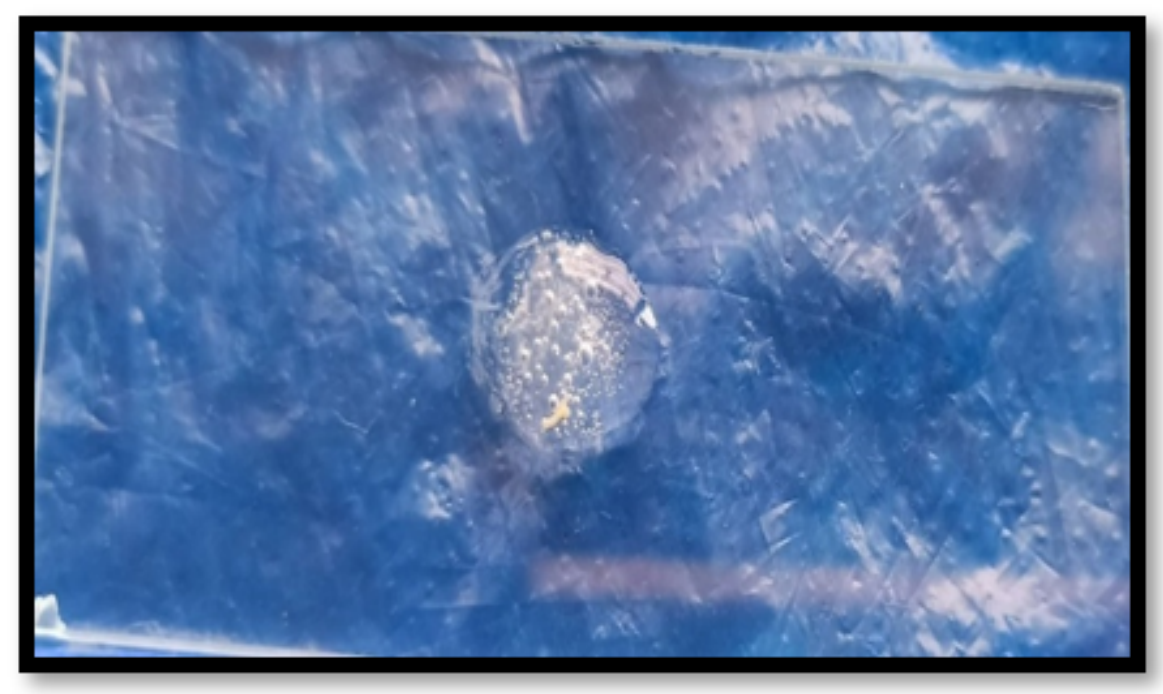

Figure 14

Results of biochemical tests and catalase test for Staphylococcus aureus

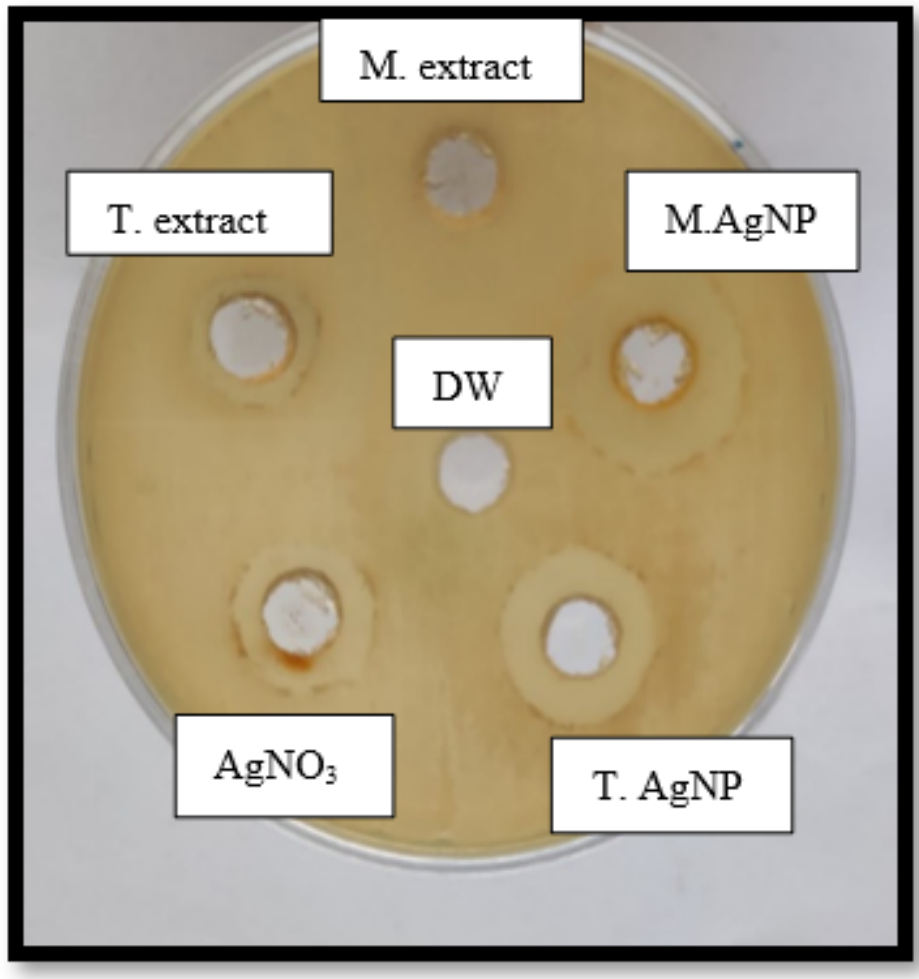

Figure 15

ZOI of Moringa oleifera leaf extract, Tamarindus indica fruit extract, AgNO3 solution, AgNP's for pure cultures of Staphylococcus aureus 


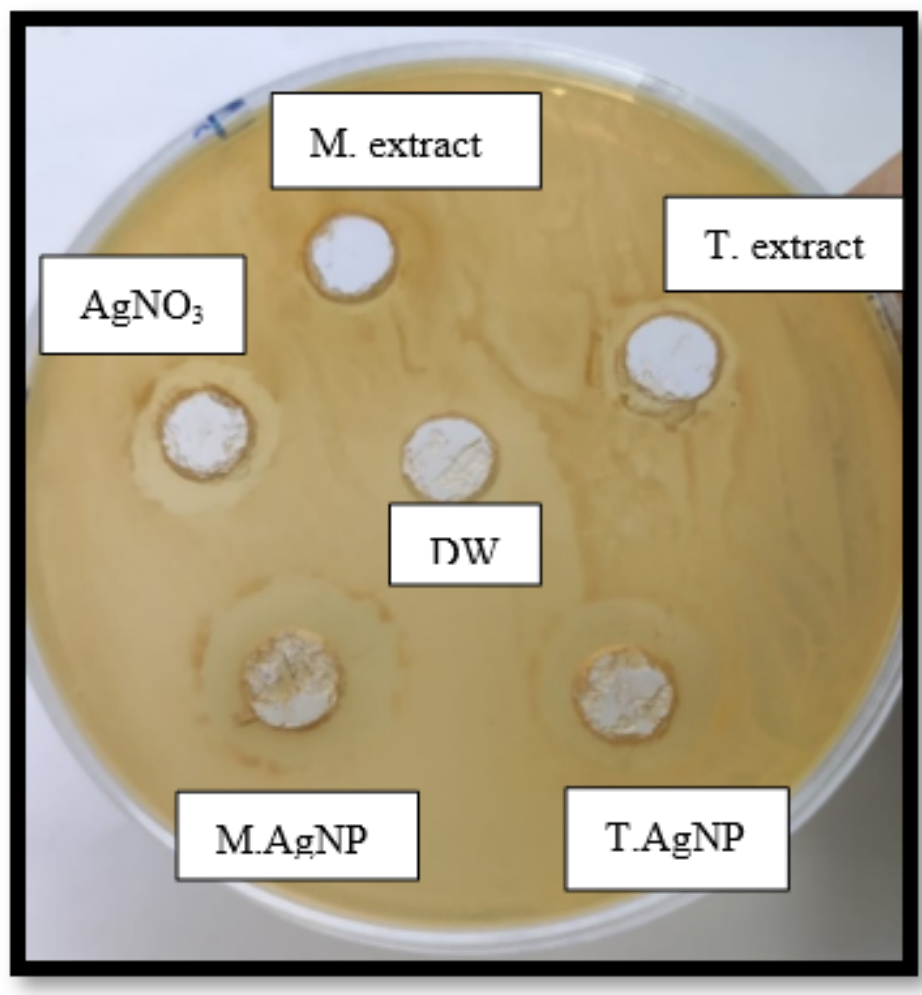

\section{Figure 16}

ZOI of Moringa oleifera leaf extract, Tamarindus indica fruit extract, AgNO3 solution, AgNP's for isolates of Staphylococcus aureus M. AgNP: Moringa oleifera silver nanoparticles T. AgNP: Tamarindus indica silver nanoparticles AgNO3: Silver nitrate solution; DW: Distilled water T. extract: Tamarindus indica fruit extract M. extract: Moringa oleifera leaf extract

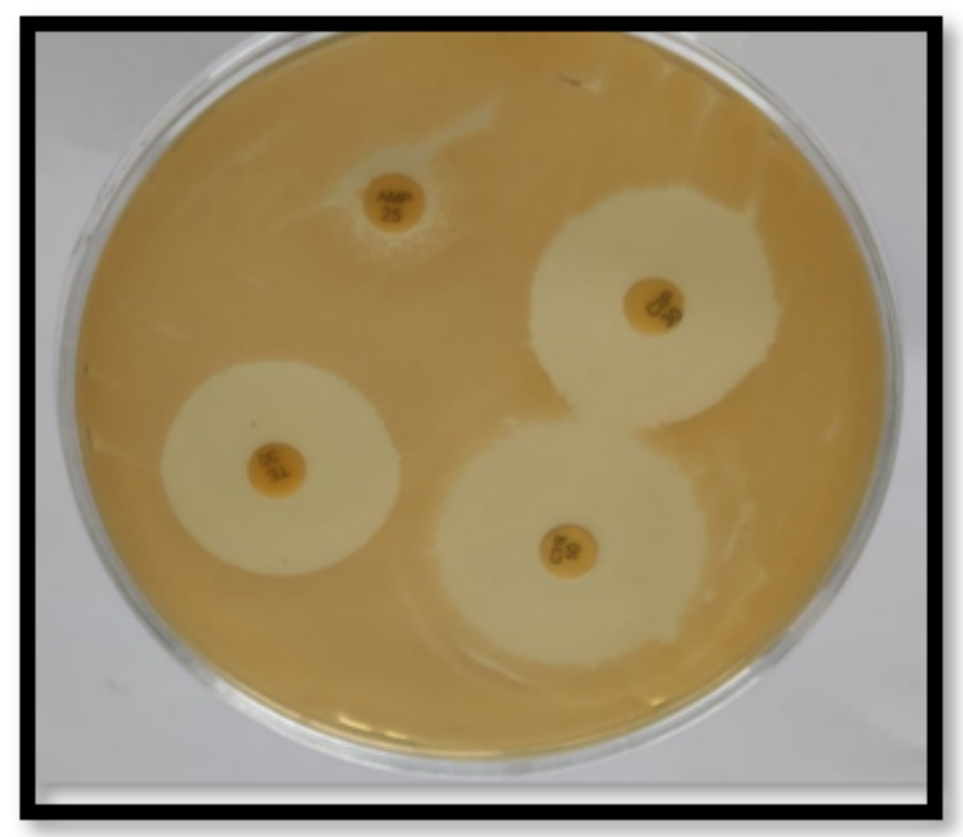


Figure 17

ZOI of antibiotics for pure cultures of Staphylococcus aureus

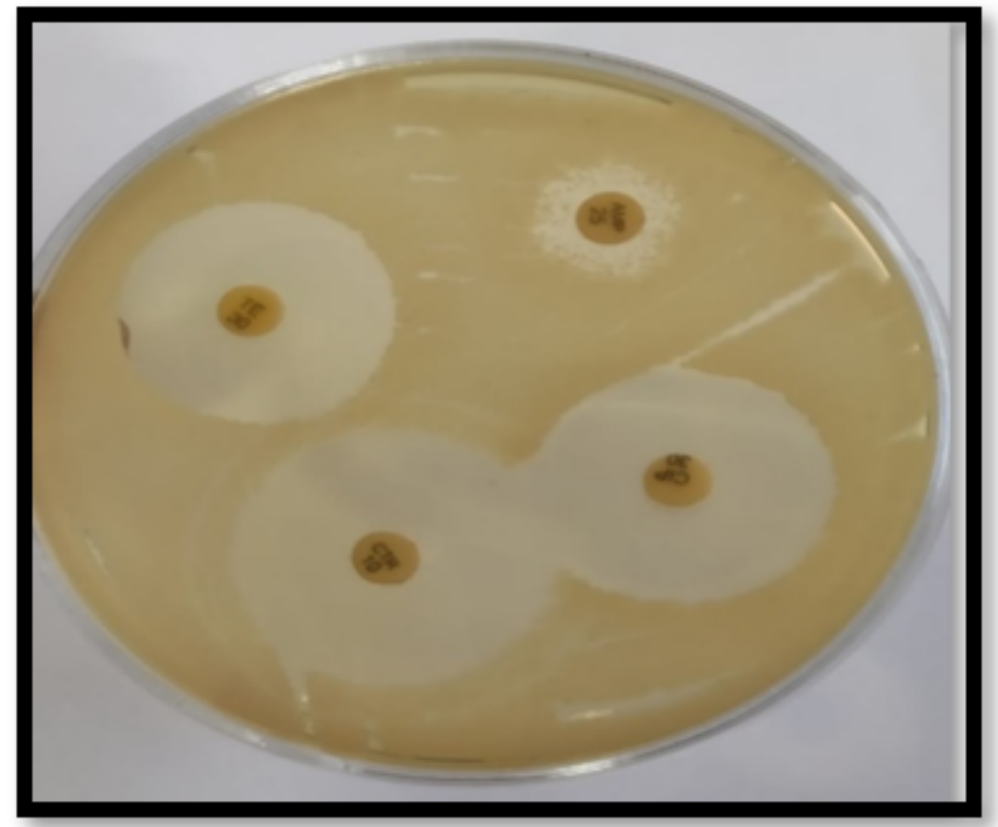

Figure 18

ZOI of antibiotics for isolates of Staphylococcus aureus 